\title{
INVENTARISASI SUKU Euphorbiaceae, Phyllanthaceae DAN Putranjivaceae DI KEBUN RAYA EKA KARYA BALI : UPAYA MELENGKAPI PEMBUATAN BUKU FLORA OF BALI
}

\author{
Tutie Djarwaningsih \\ "Herbarium Bogoriense” Bidang Botani, Pusat Penelitian Biologi, Cibinong Science Center - LIPI. \\ Jl. Raya Jakarta-Bogor Km. 46, Cibinong 16911 \\ email : tutie_teresia@yahoo.com
}

Diterima : 08 Juni 2016 Ditinjau : 05 Oktober 2016 Disetujui : 28 Oktober 2016

\begin{abstract}
Abstrak. Inventarisasi flora merupakan salah satu kegiatan utama Puslit Biologi-LIPI (khususnya bidang Botani) yang dilakukan guna mengungkap keanekaragaman biota yang berada di suatu area. Puslit Biologi sejak tahun 2000, menitik beratkan kegiatan tersebut guna mengungkap kekayaan flora pulau-pulau kecil di sekitar pulau Jawa, Sumatra, Sulawesi, Maluku, Papua dan Kepulauan Sunda Kecil (LSI). Pulau Bali mendapatkan prioritas pertama (2013-2017), karena data dasar telah tersedia berupa buku checklist. Guna melengkapi pembuatan Flora of Bali dilakukan inventarisasi suku Euphorbiaceae, Phyllanthaceae dan Putranjivaceae, yang pada awalnya berasal dari suku Euphorbiaceae di Kebun Raya Eka Karya Bali (KREKBali) yang terletak di Candikuning, Baturiti, Kabupaten Tabanan, Bali. Selain inventarisasi, bahan yang digunakan adalah spesimen herbarium koleksi KREKBali. Metode yang dilakukan adalah memilah dan mendata semua koleksi herbarium KREKBali, kemudian dilakukan pendokumentasian. Khusus untuk koleksi hidup selain didokumentasi juga dikoleksi untuk dibuat spesimen herbariumnya. Tujuan dari inventarisasi ini adalah salah satu upaya untuk menyusun Flora of Bali dengan menggabungkan marga dan jenis yang telah terdaftar dalam checklist Flora of Bali dan selanjutnya akan dibuat pertelaan, kunci identifikasi, manfaat dan persebarannya. Hasil dari kegiatan ini telah terdata: Euphorbiceae 14 jenis, Phyllanthaceae 11 jenis dan Putranjivaceae 1 jenis.
\end{abstract}

Kata kunci: Euphorbiaceae, Phyllanthaceae, Putranjivaceae, inventarisasi, Kebun Raya Eka Karya Bali (KREKBali).

\begin{abstract}
Inventory of flora is one of the main activities of the Research Center for Biology-LIPI (especially in the Botany Division), which conducted to reveal the diversity of biota in an area. Since 2000, Research Center for Biology, focuses on these activities in order to reveal the rich flora of the small islands around the island of Java, Sumatra, Sulawesi, Maluku, Papua and the Lesser Sunda Islands (LSI). The island of Bali had first priority (2013-2017), since the basic data have been available in checklist. In order, to complete of the Flora of Bali is conducted an inventory of Euphorbiaceae, Phyllanthaceae and Putranjivaceae, which was originally derived from Euphorbiaceae in Eka Karya Botanical Garden (KREKBali) located in Candikuning, Baturiti, Tabanan, Bali. In addition to the inventory, also used material of herbarium specimens KREKBali. The method to do was selected and recorded all KREKBali herbarium collections, then do documentation. Special for fresh collections, than is documented and also made for herbarium. The purpose of this inventory is one of the efforts for the preparation of Flora of Bali by combining genera and species that have been listed in the checklist Flora of Bali and will be made descriptions, identification keys, benefits and distribution. The results of this activity has been recorded: Euphorbiaceae 14 species, Phyllanthaceae 11 species and Putranjivaceae 1 species.
\end{abstract}

Keywords: Eka Karya Botanical Garden (KREK Bali), Euphorbiaceae, Phyllanthaceae,, Putranjivaceae, inventory 


\section{PENDAHULUAN}

Inventarisasi flora merupakan salah satu kegiatan utama Puslit Biologi (khususnya bidang Botani) yang dilakukan guna mengungkap keanekaragaman biota yang berada di suatu area. Puslit Biologi sejak tahun 2000, menitik beratkan kegiatan tersebut guna mengungkap kekayaan flora pulau-pulau kecil di sekitar pulau Jawa, Sumatra, Sulawesi, Maluku, Papua dan Kepulauan Sunda Kecil (LSI). Pulau Bali mendapatkan prioritas pertama (2013-2017), karena data dasar telah tersedia berupa buku checklist yang terbit pada tahun 2013.

Guna melengkapi pembuatan Flora of Bali dilakukan inventarisasi Euphorbiceae Phy llanthaceae dan Putranjivaceae, yang pada awalnya berasal dari suku Euphorbiaceae di Kebun Raya Eka Karya Bali (KREKBali). KREKBali terletak di Candikuning, Baturiti, Kabupaten Tabanan, Bali pada ketinggian 1.200-1.450 m dpl (Siregar et al, 2004). Luas kawasan Kebun Raya tersebut awalnya 50 ha, tetapi saat ini luasnya sudah mencapai 157,5 ha. Pada awalnya KREKBali hanya diperuntukkan bagi tetumbuhan runjung dan memiliki beberapa koleksi tanaman yang dikelompokkan berdasarkan kekerabatannya. KREKBali terletak di tengah-tengah Pulau Bali, yakni berada di kaldera bekas gunung berapi. Selain dikoleksi, jenis-jenis tanaman tersebut juga diupayakan penelitian dan pengembangannya (Anonim, 2013). Kebun ini didirikan pada 15 Juli 1959 dan merupakan kebun raya pertama yang dikembangkan oleh bangsa Indonesia. KREKBali secara struktur organisasi berada di bawah Pusat Konservasi Tumbuhan Kebun Raya Bogor - LIPI (Siregar et al, 2004).

Seiring dengan perkembangan dan perubahan status serta luas kawasan konservasi ex-situ bagi tropika kawasan timur Indonesia yang mempunya habitat pegunungan basah. Saat ini koleksinya terdiri dari 160 suku, 677 marga, dan 1420 jenis (mencakup 34 jenis jenis yang dilindungi dan terancam punah berdasarkan PP.No 7 thn 1999, SK. Mentan No 54/Kpts/Um/2/1972, SK.Menhut No 261/Kpts-IV/1990 dan 200 jenis langka berdasarkan Mogea dkk.(2001) dan IUCN) (Siregar et al, 2004). Tujuan dari inventarisasi masing-masing marga, jenis Euphorbiaceae, Phyllanthaceae dan Putranjivaceae adalah sebagai salah satu upaya untuk melengkapi penyusunan Flora of Bali dengan menggabungkan marga dan jenis dari sukusuku tersebut yang telah terdaftar dalam checklist Flora of Bali dan selanjutnya akan dibuat pertelaan, kunci identifikasi, manfaat dan persebarannya.

\section{BAHAN DAN METODE}

Dalam upaya menyusun Flora of Bali, bahan yang digunakan berupa spesimen herbarium koleksi Kebun Raya Eka Karya Bali (KREKBali), spesimen herbarium yang berasal dari Bali dan disimpan di Herbarium Bogoriense (BO), Natural History Museum (L) dan inventarisasi koleksi hidup yang ditanam di KREKBali. Adapun metode yang dilakukan adalah memilah dan mendata semua koleksi herbarium KREKBali, kemudian dilakukan pendokumentasian. Khusus untuk koleksi hidup selain didokumentasi juga dikoleksi untuk dibuat spesimen herbariumnya. Untuk penyusunan Flora of Bali akan disajikan pertelaan, kunci identifikasi, manfaat, dan persebarannya dari masing-masing jenis.

\section{HASIL}

Pendataan terhadap koleksi hidup yang ditanam di KREKBali dilakukan pada semua jenis-jenis Euphorbiacae maupun jenis-jenis dari suku-suku yang dahulu berasal dari Euphorbiacae, yaitu Pandaceae, Phyllanthace ae dan Putranjivaceae. Khusus untuk koleksi yang sedang berbunga maupun berbuah terutama dari kawasan Bali diupayakan untuk dibuat herbariumnya dan didokumentasikan. Inventarisasi untuk keperluan Flora of Bali tidak hanya dilakukan didalam kebun raya namun juga dilakukan di sepanjang perjalanan dari Denpasar ke KREKBali maupun sebaliknya.

Di dalam kebun, koleksi Euphorbiaceae dijumpai di blok X. C.; XII.C.1.; XIII. K. ; XV.B dan XVIII.A. Phyllanthaceae dijumpai di blok X.C.; XII.C.1. dan XIII.K.; sedangkan Putranjivaceae dijumpai di blok XII.C.1. Koleksi hidup yang dijumpai di kebun tersebut ada 26 jenis terdiri dari: Euphorbiceae 14 
jenis, Phyllanthaceae 11 jenis, Putranjivaceae 1 jenis (Tabel 1, Gambar 1 dan 2). Sedangkan Jenis-jenis dari Pandaceae tidak ditemukan koleksinya di KREKBali. Jenis-jenis tersebut tidak semuanya sedang berbunga atau berbuah.
Karenanya foto-foto yang disajikan dalam tulisan ini adalah dari jenis-jenis yang berbunga atau berbuah saja.

Tabel 1. (Jenis-jenis Euphorbiceae, Phyllanthaceae dan Putranjivaceae yang terdata di KREKBali)

\begin{tabular}{|c|c|c|}
\hline No & Euphorbiaceae & Lokasi \\
\hline 1. & Acalypha argentii & XV.B. 341, 341a \\
\hline 2. & Acalypha caturus & XII.C.1. 62 \\
\hline 3. & Acalypha hispida & X.C. $644,644 a$ \\
\hline 4. & Acalypha wilkesiana & X.C. 493 \\
\hline 5. & Aleurites moluccanus & XII.C.1. \\
\hline 6. & Cleidion javanicum $=$ Cleidion spiciflorum & XII.C.1. 63, 66 \\
\hline 7. & Codiaeum variegatum & XVIII.A. 10 a-d \\
\hline 8. & Croton argyratus & XII.C.1. 60 \\
\hline 9. & Euphorbia lactea & X.C. 828 \\
\hline 10 . & Euphorbia pulcherrima (daun muda putih) & X.C. 387 \\
\hline 11. & Euphorbia pulcherrima (daun muda merah) & X.A. \\
\hline 12. & Euphorbia tirucalli & X.C. 740 ; tanah lot \\
\hline 13. & Jatropha curcas & X.C. 173 \\
\hline 13. & Jatropha integerrima & X.C. 655 \\
\hline 14. & Jatropha multifida & X.C. 822 \\
\hline No. & Phyllantaceae & Lokasi \\
\hline 1. & Antidesma bunius & XII.C.1. 34 \\
\hline 2. & Antidesma montanum & XIII.K. 21, 21a \\
\hline 3. & Baccaurea racemosa & X.C.256, XII.C. 1.92 \\
\hline 4. & Bischofia javanica & XII.C. 1.8 \\
\hline 5. & Breynia sp. & X.C. 550 \\
\hline 6. & Cleistanthus sp. & XII.C.1. \\
\hline 7. & Glochidion obscurum & XII.C.1.86 \\
\hline 8. & Glochidion rubrum & XII.C.1. 46 \\
\hline 9. & Glochidion sp. & XII.C.1. \\
\hline 10. & Phyllanthus buxifolius & X.C. 356 \\
\hline 11. & Sauropus androgynus & XII.C.1. 147 \\
\hline No. & Putranjivaceae & Lokasi \\
\hline 1. & Drypetes sp. & XII.C.1. 260 \\
\hline
\end{tabular}

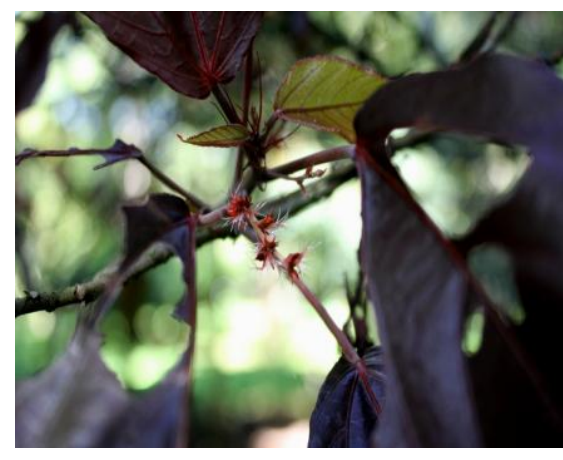

Acalypha argentii

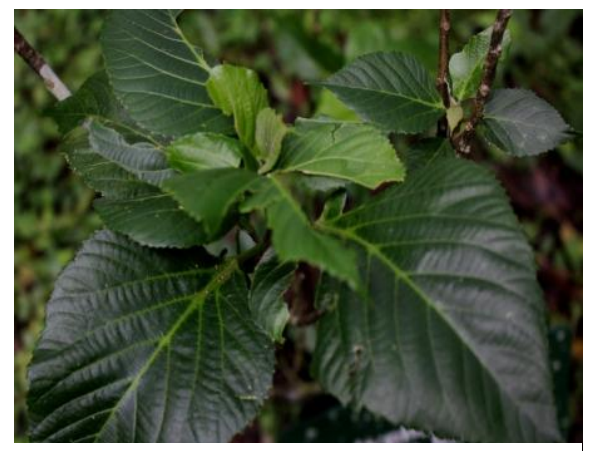

Acalypha hispida 


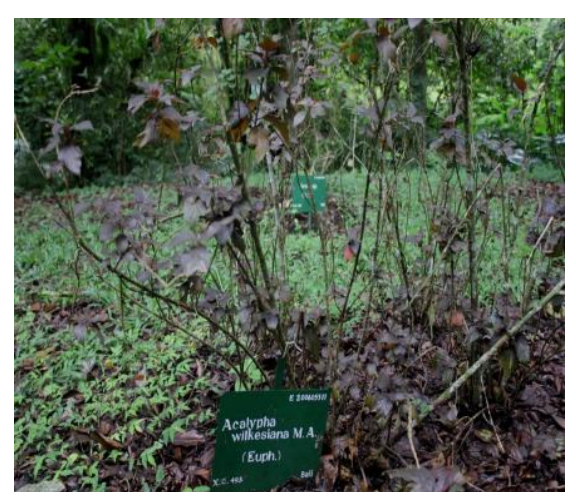

Acalypha wilkesiana

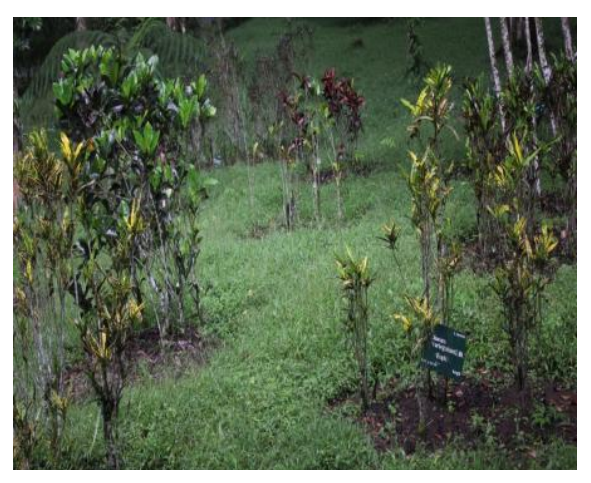

Codiaeum variegatum

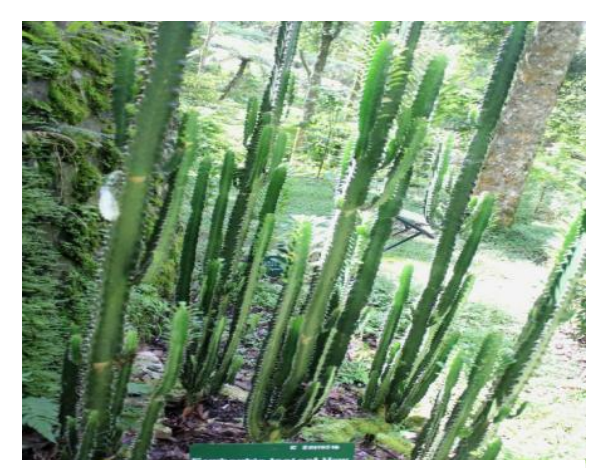

Euphorbia lactea

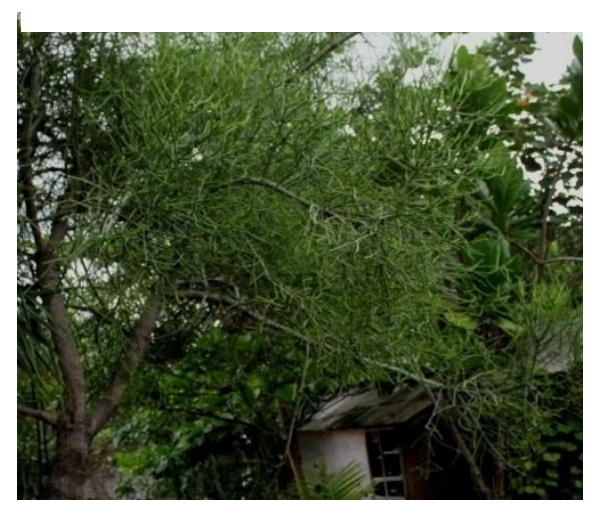

Euphorbia tirucalli

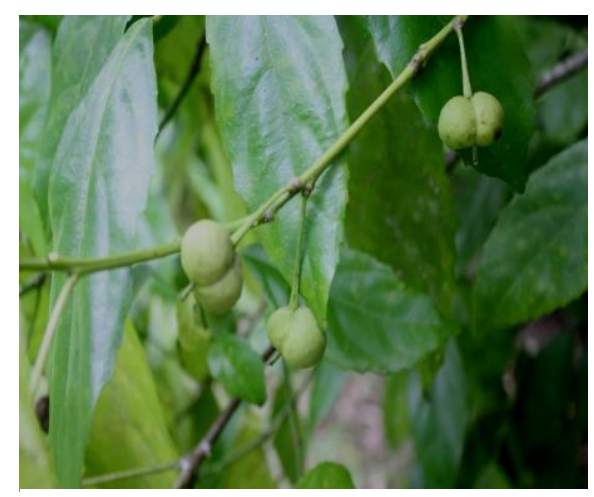

Cleidion javanicum

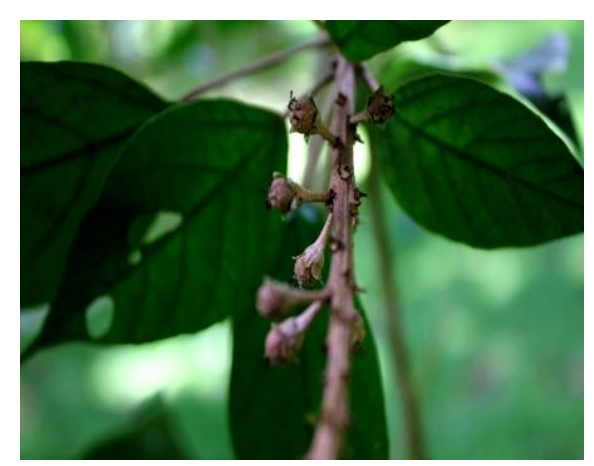

Croton argyratus

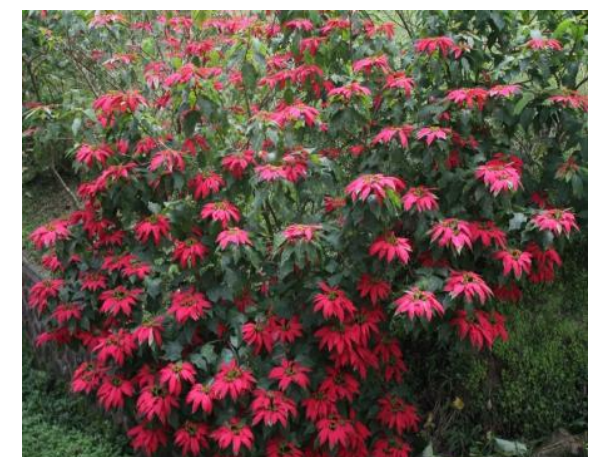

Euphorbia pulcherrima

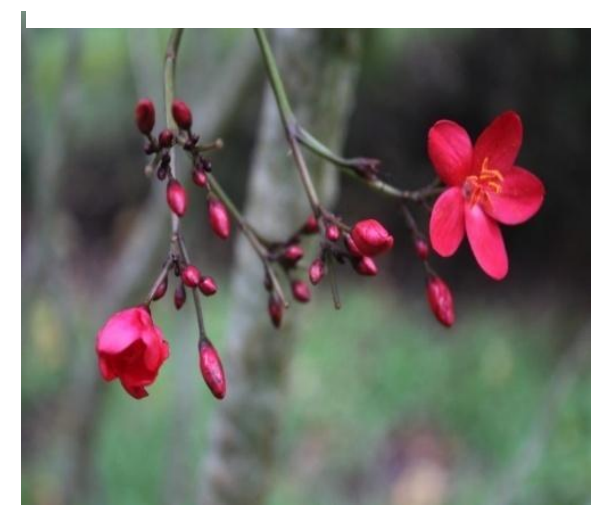

Jatropha integerrima 


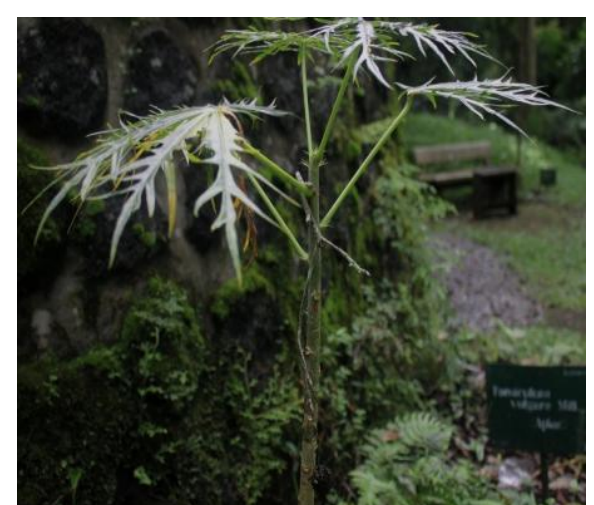

Jatropha multifida

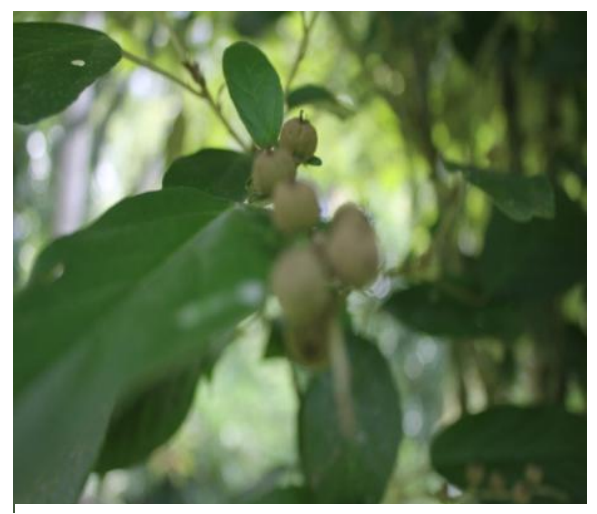

Mallotus sp.

Gambar 1. Jenis-jenis Euphorbiaceae

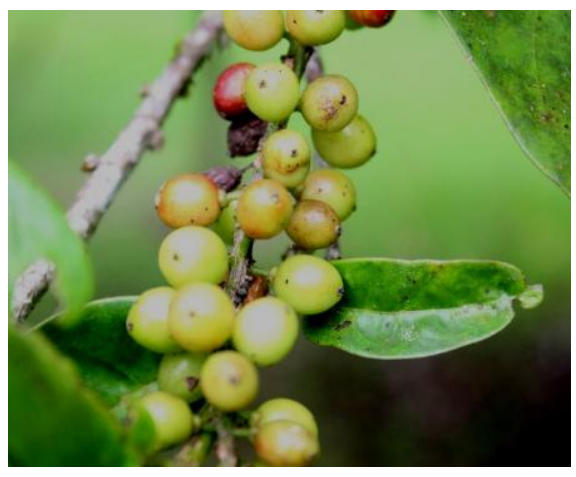

Antidesma bunius

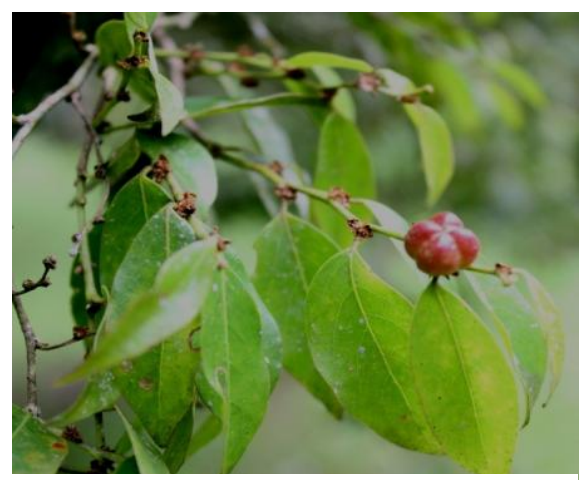

Cleistanthus sp.

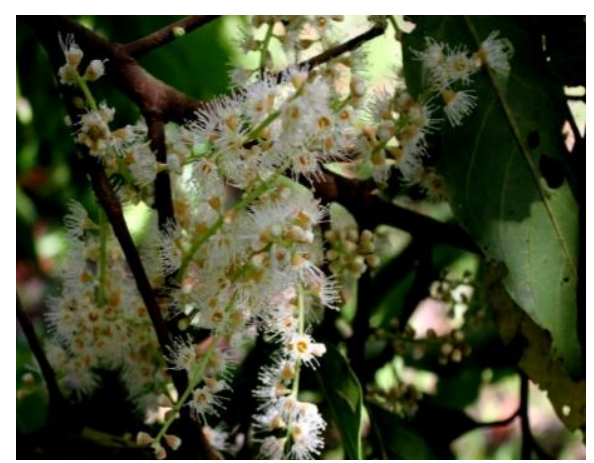

Glochidion rubrum

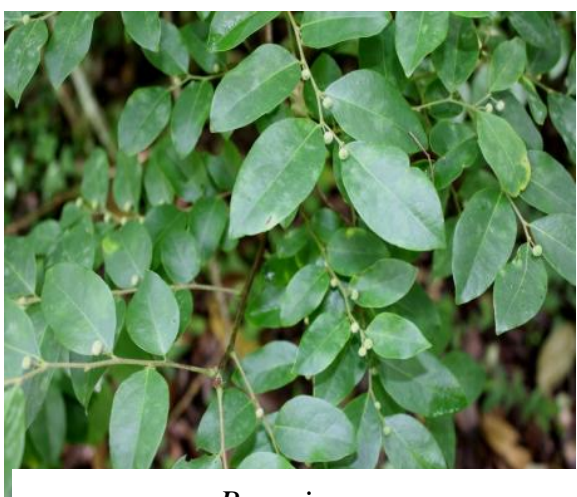

Breynia sp.

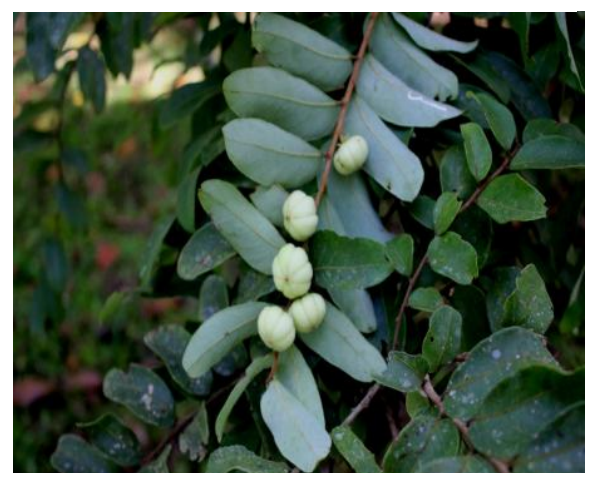

Glochidion obscurum

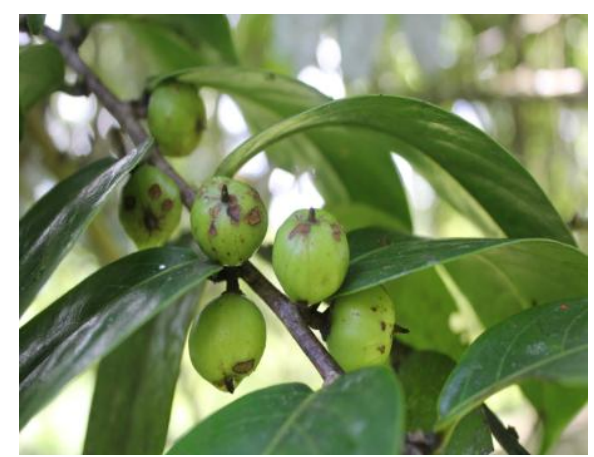

Glochidion sp. 


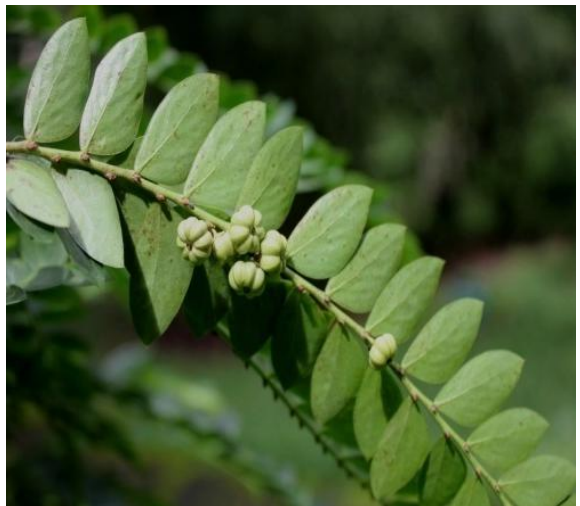

Phyllanthus buxifolius

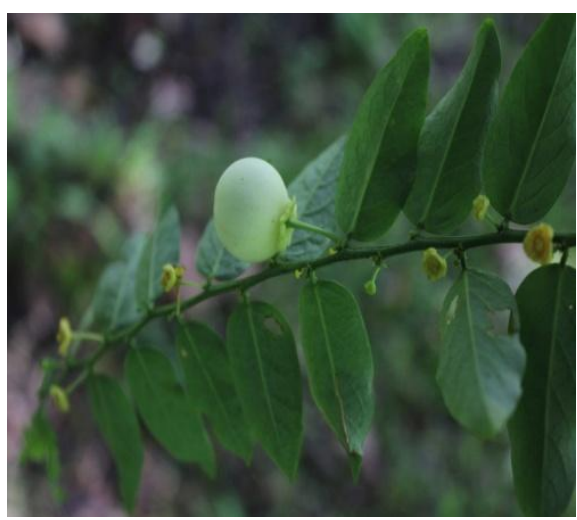

Sauropus androgynus

Gambar 2. Jenis-jenis Phyllanthaceae

\section{PEMBAHASAN}

Menurut Girmansyah et al (2013), Euphorbiaceae terwakili oleh 47 jenis dari 21 marga. Pandaceae terdiri dari 1 jenis, Phyllanthaceae tercatat 33 jenis dari 10 marga, sedangkan Putranjivaceae 2 jenis dari 1 marga. Hasil pendataan ini berdasarkan herbarium yang tersimpan di KREKBali, Herbarium Bogoriense (BO) dan Natural History Museum (L). Sedangkan berdasarkan koleksi hidup yang di jumpai di kebun ada 26 jenis terdiri dari: Euphorbiceae 14 jenis, Phyllanthaceae 11 jenis dan Putranjivaceae 1 jenis. Jenis-jenis dari Pandaceae tidak ditemukan koleksinya di KREKBali. Pada saat inventarisasi dilakukan (bulan April 2016), jenis-jenis tersebut tidak semuanya sedang berbunga atau berbuah; ini mungkin disebabkan bulan tersebut bukan merupakan saat pembungaan ataupun pembuahan untuk jenis-jenis tersebut.

Terdapat 8 jenis yang termasuk suku Euphorbiacae yang tidak tercatat dalam Girmansyah et al (2013), akan tetapi ditemukan sebagai koleksi hidup di KREKBali yaitu: Acalypha argentii, Acalypha hispida, Acalypha wilkesiana, Euphorbia lactea, Euphorbia pulcherrima (daun muda putih), Euphorbia pulcherrima (daun muda merah), Jatropha integerrima, dan Jatropha multifida. Jenis-jenis yang belum diketahui informasinya mengenai kelektor \& no koleksinya berjumlah 20, hal ini diduga karena spesimen sudah tidak dapat digunakan lagi atau sudah rusak/hancur karena serangan serangga (Girmansyah et al,
2013), yaitu: Euphorbiacae (11 jenis), Pandaceae (1 jenis), dan Phyllanthaceae (8 jenis), dari hasil pemeriksaan spesimen herbarium yang disimpan di KREKBali, hanya ditemukan 2 jenis saja yaitu: Jatropha curcas dan Phyllanthus emblica, berdasarkan koleksi hidupnya Codiaeum variegatum ditemukan di blok XVIII.A. 10 a-d, Euphorbia tirucalli ditemukan di blok X.C. 740.

Koleksi hidup yang di jumpai di KREKBali terdiri dari: Euphorbiceae 14 jenis, Phyllanthaceae 11 jenis dan Putranjivaceae 1 jenis. Delapan jenis diantaranya belum tercatat dalam checklist, sehingga nantinya akan ditambahkan pada saat penyusunan Flora of Bali. Sedangkan koleksi dari jenis-jenis Pandaceae yang tidak ditemukan koleksinya di KREKBali dan pengamatan spesimen yang belum diketahui jenis-jenisnya harus terus dilakukan inventarisasi guna memperoleh koleksi-koleksi yang memenuhi standar internasional.

\section{DAFTAR PUSTAKA}

Anonim. 2013. Kebun Raya Eka Karya Bali. (https://id.wikipedia.org/wiki/Kebun_Ray a_Eka_Karya_Bali). Diakses 25 Mei 2016. Pada pukul 11.28.

Girmansyah, D., Santika, S., Retnowati, A., Wardani, W., Haerida, I., Widjaja, E.A. \& van Balgooy, M.M.J. 2013. Flora of Bali An Annotated Checklist. Herbarium Bogoriense, Botany Division Research Center for Biology-LIPI. 
Mogea, J.P., Gandawidjaja, D., Wiriadinata, H., Nasution, R.E. \& Irawati. 2001. Tumbuhan Langka Indonesia. LIPI Seri Panduan Lapangan. Pusat Penelitian dan Pengembangan Biologi - LIPI. Balai Penelitian Botani. Herbarium Bogoriense. Bogor, Indonesia.
Siregar, M., Lugrayasa, I.N., Arinasa, I.B.K. \& Mudiana, D. 2004. An Alphabetical List of Plant Species Cultivated in 'Eka Karya' Bali Botanic Garden. Bali Botanic Garden Catalogue. Republic of Indonesia, Indonesian Institute of Sciences, Indonesian Botanic Garden. 